\title{
ESCENAS DE LA MASCULINIDAD COSPLAY: EXPLORACIONES DEL CUERPO DESEADO Y LA EXTIMIDAD
}

\author{
SCENES OF COSPLAY MASCULINITY: EXPLORING \\ THE DESIRED BODY AND EXTIMACY
}

\author{
CENAS DA MASCULINIDADE COSPLAY: EXPLORAÇÕES \\ DO CORPO DESEJADO E EXTIMIDADE
}

Jeimy Johana Acosta Fandiño ${ }^{1}$

Resumen

El presente artículo analiza varias escenas del cosplay como un espacio de creación de nuevas masculinidades en el que se ponen en tensión las categorías tradicionales. Se plantea que dicha tensión se encuentra atravesada por la articulación del mundo de la ficción y el mundo cotidiano, así como por la construcción de un cuerpo deseado en la que se pone en juego el desarrollo de un "yo".

Palabras clave: cuerpo; cosplay; masculinidad

Abstract

This paper analyzes several cosplay scenes as a space to create new masculinities in which the traditional categories are put in tension. It is argued that this tension is crossed by the articulation of the world of fiction and the everyday world, as well as by the as well as for the construction of a desired body in which the development of an "I" is put at stake.

Keywords: body; cosplay; masculinity

\section{Resumo}

\begin{abstract}
Este artigo analisa várias cenas de cosplay como um espaço para a criação de novas masculinidades em que as categorias tradicionais são postas em tensão. Argumenta-se que essa tensão é atravessada pela articulação do mundo da ficção e do mundo cotidiano, bem como pela construção de um corpo desejado no qual o desenvolvimento de um "eu” está em jogo.
\end{abstract}

Palavras-chave: corpo; cosplay; masculinidade

Fecha de recepción: 22 de septiembre de 2017

Fecha de aprobación: xx de xx de xxxx

Para citar este artículo:

Acosta, J. (2017). Escenas de la masculinidad cosplay: exploraciones del cuerpo deseado y la extimidad. Lúdica Pedagógica, 26, 129-139.

1 Actualmente docente e investigadora de la Universidad de Ibagué. Maestranda en Estudios Culturales, Universidad Nacional de Colombia y Diseñadora Industrial egresada de la Universidad Antonio Nariño. Correo electrónico: jeimy.acosta@unibague.edu.co 
La diversidad es la forma en que la vida se expresa para responder a un ambiente determinado, es la exploración de las posibilidades de existir, biológicamente hablando.

Brigitte Baptiste $^{2}$

\section{PRESENTACIÓN}

Los cosplayer representan personajes del anime. Un intérprete del cosplay elige uno de dichos personajes, confecciona el traje, acondiciona su cabello, su rostro, sus músculos, prepara la presentación de dicho personaje y luego aparece en público durante eventos de diversa índole: encuentros, concursos, pasarelas, festivales. Los cuerpos de los cosplayer se transforman durante la personificación, no solo porque ha sido acondicionado, sino porque se constituye en el vehículo de la aventura, de la fantasía: se trata de "corporalizar" a otro, de experimentar por un momento lo que ocurre en la ficción, de "incorporar", de "encarnar" a un personaje de la televisión, el cine, los videojuegos o la internet. El cuerpo es, entonces, un medio lúdico en el que los practicantes juegan con el cuerpo que poseen, y buscan así experimentar el cuerpo que desean.

Este artículo presenta resultados preliminares de una investigación en curso sobre las masculinidades en el cosplay, parte de la investigación de Maestría en Estudios Culturales de la Universidad Nacional de Colombia y que apoya la Universidad de Ibagué. Para la primera parte, dicha investigación ha desarrollado dos estrategias de recolección de información: 1) observación de eventos cosplay, donde se realizaron entrevistas semiestructuradas, registro fotográfico y apuntes en una libreta de campo, y 2) etnografía virtual a partir del seguimiento sistemático de páginas web y fanpage relacionadas con esta práctica. La investigación se ha concentrado en el seguimiento a dos comunidades cosplay de Bogotá: Sailor Moon y Saint Seiya. Inicialmente, se plantearán las coordenadas conceptuales del análisis, para luego dar cuenta de tres escenas que describen aspectos centrales de la construcción de las masculinidades, específicamente la tensión entre el intérprete y el personaje,

2 Brigite Baptiste o Luis Guillermo Baptiste es una bióloga colombiana, experta en temas ambientales y biodiversidad. El epígrafe es tomado de una de sus entrevistas en las que define la biodiversidad (https://bit.ly/2uGZlsO). esto es, la problematización de la corporalización ("encarnación") de un dibujo animado, el proceso complejo a través del cual un cuerpo humano, asume características de un cuerpo no humano.

Ahora bien, el cosplay surge en Japón hacia 1970, en los mercados de cómics ${ }^{3}$ japoneses. Los admiradores de los anime, manga y video juegos gustaban de las representaciones de los diferentes personajes que allí se realizaban. Sin embargo, Ferrari (2014) menciona que, en algunas convenciones de películas de ficción de los años 1930 en Estados Unidos, los fans se vestían como los personajes, lo que se constituye en un antecedente del cosplay. En la década de 1980, Nobuyuki Takahashi publicó materiales de lo que denominó cosplay, una contracción de costume play (juego del disfraz). Según esta autora, dicha práctica llega a Brasil desde los años 1990. Puede decirse que el universo cosplay poco a poco fue llegando a Latinoamérica a través de diversos medios y cada vez tiene más practicantes. De acuerdo con lo observado en los eventos amateur, el cosplay no tiene límites de edad e incluso en algunos casos es una experiencia familiar.

Aunque inicialmente el cosplay surge como una práctica de disfraz (asumir la apariencia de un personaje en una fecha y lugar específico ${ }^{4}$ ), los cosplayers consideran su quehacer como una personificación, lo que implica lograr tanto los rasgos físicos como los ademanes y posturas que contribuyan a la caracterización fiel del personaje.

En Colombia, el cosplay lleva varios años, sin embargo, por su estrecha relación con el manga y el anime, se puede suponer que esta práctica inicia en Colombia en los años 1990, cuando el anime se

3 Eventos muy similares a los que se realizan en Corferias en Bogotá: bajo una temática se congregan los productores y consumidores de determinados productos, en este caso del manga, anime, videojuegos, entre otros. Ver: http:// jimenarangel1106.blogspot.com/2011/11/informacion-para-miproyecto-de.html

4 En los carnavales, por ejemplo, el disfraz sirve de medio para la sátira y la burla, para ridiculizar a los políticos, a sacerdotes, a los superhéroes, incluso a quien lleva el traje, todo al mismo tiempo: que una persona gorda tenga atuendo de Batman, genera un efecto cómico en la medida en la que los "músculos" de plástico no "coinciden" con la figura en cuestión. Ver: Prat, J. (1993). "El carnaval y sus rituales. Algunas lecturas antropológicas". Revista Temas de Antropología Aragonesa, n. ${ }^{\circ}$ 34, pp. 278-296. Los practicantes del cosplay se esfuerzan por personificar al personaje que han elegido, por verse, moverse e incluso, sonar como este, de hecho, para algunos cosplayers, la palabra disfraz es un insulto. 
populariza a través de series como: Super Campeones, Caballeros del Zodiaco y Sailor Moon. Sin embargo, eventos de encuentro masivo reconocidos inicia en Colombia hacia el 2009, como es el caso del Salón del Ocio y la Fantasía $\left(\mathrm{SOFA}^{5}\right)$, realizado anualmente. Existen eventos cosplay en Bogotá desarrollados en la Biblioteca Virgilio Barco, la Universidad Nacional o en el Parque de los Novios ${ }^{6}$. Estos eventos, cuentan con un carácter performativo ${ }^{7}$, en este sentido, la personificación cosplay se puede entender como un proceso de construcción de relaciones sociales basadas en "la fantasía", en las ficciones, en la construcción de narraciones que apelan al anime. Vale la pena decir que los eventos "producen" unos espacios extraordinarios, no ordinarios, en los que los personajes pueden actuar, transgredir las normas del vestido y la presentación de la vida ordinaria y cotidiana.

La práctica en Colombia presenta diferentes perspectivas: para algunos el cosplay es disfrazarse, divertirse, jugar y compartir con los amigos, tal como lo menciona Carlos Pérez de Bucaramanga, quien en el SOFA 2014 personificó a Uzu Sanageyama de la serie Kill la Kill; para otros el cosplay no es un juego, ni disfrazarse, se trata de personificar, de recrear un personaje, y parte de esa construcción los lleva a confeccionar sus atuendos para lograr mayor realismo. Por tanto, la práctica del cospaly se desenvuelve en diferentes dinámicas y perspectivas.

Existen varios estilos para realizar cosplay:

1. Tradicional: La personificación sexo/género, es decir, una mujer solo interpreta personajes femeninos y un hombre solo personajes masculinos.

2. Crossplay, en el que un hombre interpreta personajes femeninos o una mujer personajes masculinos.

5 El Salón del Ocio y la Fantasía (SOFA) es una feria anual de pasatiempos y entretenimiento, celebrada en Bogotá (Colombia). Este evento inició en 2009 en el Centro Comercial Bima y, desde 2010 se realiza en Corferias. sofa presenta temáticas como: videojuegos, tatuaje, maquillaje, circo, deportes key-pop y jey-pop entre otras actividades.

6 Datos suministrados por Jake, una de las personas entrevistadas en Sofa 2014.

7 En el sentido que le da a esta palabra Butler (1997). Es decir, se trata de actuaciones, de secuencias de acción que cristalizan el sentido social.
3. Gender Bender, en el que se crea la versión de género contraria a la del personaje, por ejemplo, cuando se personifica a Naruto (héroe masculino) como una mujer.

4. Kugurumi, consiste en la utilización de atuendos que evocan un personaje animal, pero que no cuentan con el detalle del anime.

5. Furry, personificación de animales en la que se utilizan máscaras.

6. Animegao, que pretende emular por completo el personaje, recurriendo a máscaras o maquillaje para captar cada característica de este.

7. Meca, que es la caracterización de robots.

Todas estas formas de caracterización ya se encuentran en Bogotá ${ }^{8}$. Ahora bien, las escenas que a continuación se presentarán aluden al modo como algunos cosplayer experimentan la representación, así como a algunas tensiones que la representación genera en experiencias amateur.

\section{COORDENADAS: CUERPO, GÉNERO Y MÍMESIS}

Según Mara Viveros, "el género y la sexualidad son construcciones históricas y culturales" (2006, p. 15), por tanto, abordar el tema de masculinidad implica tener en cuenta el contexto social al que corresponde. El cosplay permite identificar varias dinámicas de dicho contexto. Así, las representaciones andróginas son aceptadas en el contexto de juego cosplay, pero cuando el intérprete sale de este ámbito, los ademanes y modificaciones corporales (cabello tinturado, maquillaje, etc.) ya no son tan bien recibidas, tal como lo manifiesta Jake: "Ya en el exterior [cuando está fuera del personaje] me critican mucho por tener el cabello así". Durante el sofa de 2014, este joven narró lo incómodo que se siente fuera del ámbito de juego, pues se convierte en objeto de burla de quienes ponen en duda su "hombría", al tener el cabello de colores no convencionales. Existe, entonces, un campo problemático relacionado con la construcción corporal de las masculinidades en el cosplay, pues la creación de espacios lúdicos puede colisionar con algunos cánones corporales. Duch y Mèlich plantean una tensión pertinente para el presente caso:

8 Esta caracterización parte de lo observado en SOFA 2014, de las entrevistas desarrolladas allí y de la consulta a varias fuentes de internet (ver: https://bit.ly/1lhK3eZ y https://bit.ly/2zv1cX8). 
Como es sabido, en la mitología cartesiana la imagen ideal del ser humano se caracteriza por un estricto control racional, para la exhaustiva planificación de todos los pensamientos y de todas las actividades de la existencia humana y por la expulsión de los sentimientos. En cambio, en la mitología postcartesiana y postmoderna, la imagen del hombre se distingue por una aguda conciencia de finitud y por la búsqueda, a menudo entre angustiada y narcisista, de satisfacciones personales mediante unas nuevas formas de intimidad y unas nuevas "técnicas" para acceder a las "vivencias". (2005, p. 235).

Las personificaciones cosplay se ubican en ese universo poscartesiano de búsqueda de experiencias. En esta discusión entre la racionalidad y la lúdica, se encuentra en juego la separación cuerpo-mente propio del mundo moderno. De un lado, los disciplinamientos que demanda el trabajo, del otro, los desplazamientos en pro de la "liberación" de las ataduras y controles sobre cuerpo. Pues bien, estas liberaciones son paradójicas, ya que remiten a nuevas formas de sujeción (como el narcisismo, ver Mejía, 2009): los cuerpos se mueven en el terreno de los deseos, entrampados en la búsqueda de satisfacciones. Los cuerpos se convierten en instrumentos de la movilidad y la productividad, del trabajo y del consumo (Castro-Gómez, 2009).

Para Turner (1989), se han desarrollado dos tradiciones sobre el estudio del cuerpo. La primera de ellas sigue el constructivismo posestructuralista que entiende a las instituciones como entidades arbitrarias que producen objetivaciones del cuerpo (discursos, dispositivos) y formas de control que modulan las fuerzas y posibilidades del cuerpo. La segunda tradición sigue el legado fenomenológico que se centra en la experiencia corporal. Según Turner, no se puede desconocer el papel del poder en la construcción de representaciones del cuerpo y los modos como a través de tales representaciones se establecen procesos de sujeción social. Pero es necesario reconocer las formas como la vida cotidiana vive el cuerpo, se reelaboran dichas representaciones y se experimenta el ser. El cosplay se encuentra en esta tensión entre la liberación y las nuevas formas de control social que operan a través de los mercados del entretenimiento.
De otro lado, el cuerpo sintetiza la construcción de sentido, de modo que las técnicas corporales apuntan hacia la reproducción de las prácticas sociales:

El cuerpo es el asiento de la estructuración social que hace posible la realización de las acciones y su reproducción como parte fundamental de la actividad cotidiana. De modo que toda representación y cognición queda determinada por la historia corporal y social de nuestras interacciones. La expresión corporal se puede moldear socialmente, y aquí la transmisión de las técnicas corporales cumple un papel central como proceso reproductivo de capacidades prácticas y simbólicas que fluyen en la corporalidad de las personas y que dotan de sentido sus acciones. (García, 2009).

Todo este proceso se encuentra en el meollo de la relación entre el individuo y la sociedad. Dicha relación se vincula con la reproducción del orden social, de modo que dicho orden se despliega a través del sentido kinésico, sentido que constituye dimensiones subjetivas e intersubjetivas. En esta misma dirección, las "inscripciones" corporales como los ropajes, las modas, los accesorios y las prótesis apuntan a la manera como cada quien construye una corporalidad, a la manera como se relaciona el yo y el cuerpo. En este punto cabe una referencia central respecto al cosplay: la tensión entre el cuerpo heredado y el cuerpo deseado. Se trata de la distancia entre la imposición biológica (color de piel, de cabello, estatura, tamaño y forma de las partes del cuerpo, etc.) y el cuerpo que cada quien se afana por adquirir (Gómez y González, 2007). En este escenario, algunos teóricos apuntan a las metáforas de los zombis y cíborg:

Los cuerpos son tanto zombies como cyborg. Nunca hemos tenido una mente propia y usualmente actuamos involuntariamente - condicionados y externamente dirigidos-. Desde que evolucionamos como homínidos y desarrollamos la locomoción bípeda, dos miembros se volvieron manipuladores y construimos artefactos y máquinas. En otras palabras, siempre hemos estado acoplados a la tecnología. Siempre hemos sido cuerpos con prótesis. Tememos lo involuntario y nos estamos volviendo cada vez más automatizados y con extensiones. Pero tememos lo que siempre hemos sido y a aquello en que ya nos hemos convertido - 
zombies y cyborgs-. (Stelarc, citado por Pinzón, Garay y Suárez, 2004).

Las personificaciones o encarnaciones cosplay, en cuanto exploración lúdica que apela al manga y a la industria del entretenimiento se encuentra entre la re-existencia (invención de modos diferentes de ser) y los dispositivos hegemónicos. Esa tensión se puede leer desde lo que Paula Sibilia (2009) denomina "extimidad". Si otrora los sujetos apelaban a espacios íntimos (relativamente aislados en los que se entregaban a sus gustos y cavilaciones) para dar cuenta de sí mismos (subjetividad introdirigida), hoy, con la multiplicación de las ventanas (de las pantallas interactivas en las que cualquiera puede "entrar" en tu alcoba), los sujetos se construyen a sí mismos a través de una permanente exhibición (subjetividad alterdirigida) de la extimidad. En esta escena, los sujetos devienen en empresarios de sí mismos, esto es, en personas preocupadas por hacer de sí una "marca", de cuidar su nombre, de cultivar tanto sus habilidades como sus relaciones. Algunos de los cosplay entrevistados se vienen constituyendo en una empresa unipersonal, pues los contratan para presentaciones y eventos de diversa índole. Sin embargo, al parecer, la marca, el producto, es el personaje, no la persona: se contrata a "Naruto" (a la buena representación de este) y no tanto al "actor", se prioriza al maniquí.

Por otro lado, Jauss (1992) presenta la idea de experiencia estética en la cual la lúdica y el juego es parte primordial en la creación de mundos extraordinarios; dichas propuestas desarrollan símbolos que permiten salir de la vida cotidiana a través de la imaginación. Desde esta perspectiva, se puede entender la propuesta del cosplay como una apuesta por entrever esos mundos posibles, propuesta que no solo se recrean en la imaginación de los observadores, sino que se materializan a través de los cuerpos.

Ahora bien, el cosplay como práctica de la personificación y la exhibición se encuentra en el meollo de la invención de sí mismo y la reproducción de aparatos de regulación social centrados en el narcisismo. Las siguientes escenas permiten abordar esta cuestión de cara a la construcción social e histórica de la masculinidad. Es necesario mencionar que existen dos tipos de cosplay, que los practicantes refieren como "profesional" y "amateur". Se presentará primero el trabajo de Fito Rey, cosplayer ganador de diversos concursos en el país. Luego se referirá un evento amateur organizado en mayo del 2015. Finalmente, se presentará un caso de matoneo contra una personificación de Sailor Moon.

\section{LOS PROFESIONALES}

Este tipo de cosplay depende de qué tan diestro sea el cosplayer para presentarse en competencia, acumular experiencia y algunos triunfos. Los intérpretes profesionales tienden a ser estrictos con respecto al parecido de su interpretación con el personaje original, para lo cual algunos también desarrollan la práctica cosmaker, lo que quiere decir que crean sus propios trajes; este aspecto es fundamental, ya que la mayoría de los concursos lo requieren. Aunque lo estricto de las reglas para la presentación de los personajes depende de cada concurso, si tales eventos

\section{Figura 1. Kratos, interpretación de Fito Rey}

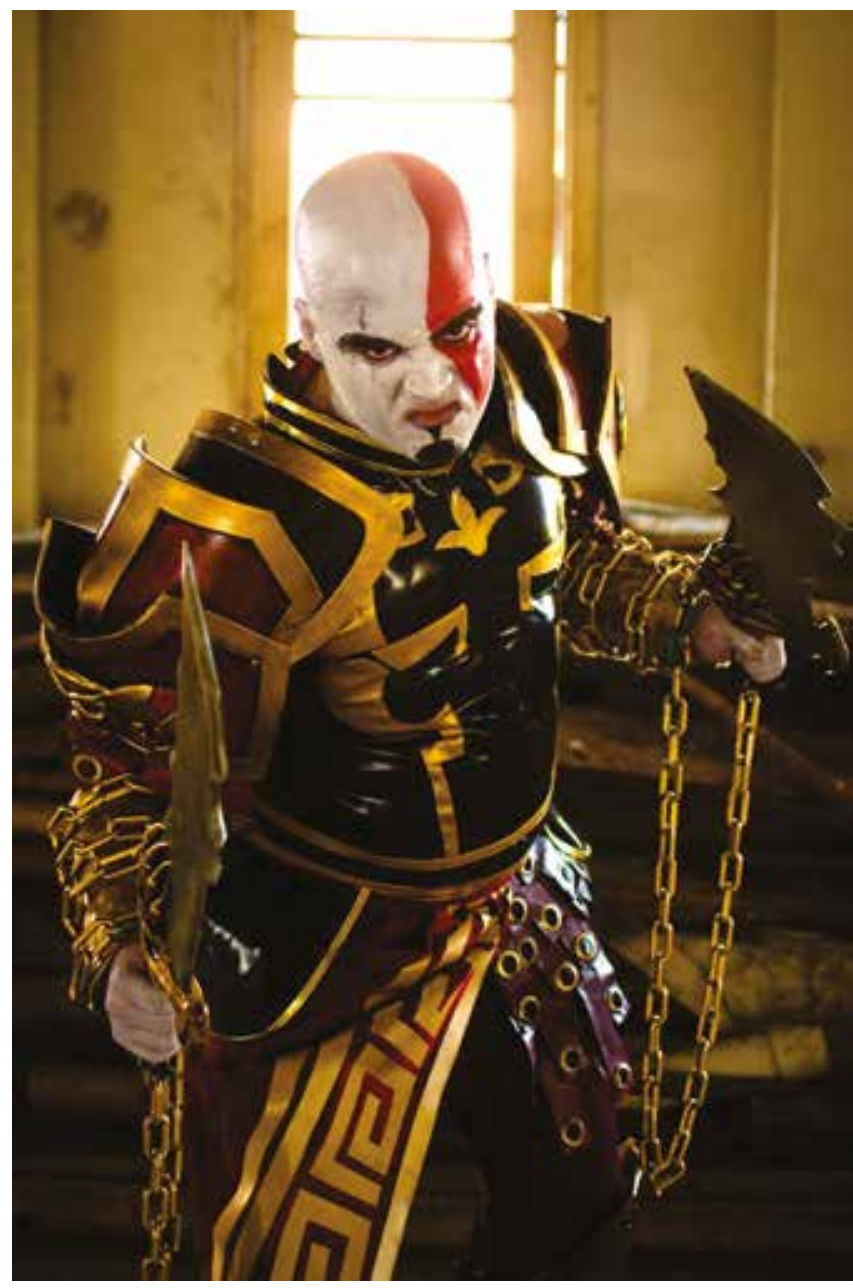

133 
lo ameritan, la personificación debe ser precisa. Pero si existe la oportunidad, el cosplayer juega tanto con el personaje como con el público. Para explicar este punto se acudirá a un caso específico, el de Fito Rey, un cosplayer que ha sido ganador de varios concursos, entre ellos, el Yamato Cosplay Cup del $2014^{9}$.

Por lo general, los concursos de cosplay incluyen tres tipos de presentación, las cuales se definen según la necesidad del concurso. Estas pueden ser: 1) pasarela, 2) presentación tradicional y 3) presentación libre. 1) La pasarela requiere un desfile del personaje, exhibiendo el atuendo como centro de atención, el modelo debe evocar movimientos, gestos ademanes del personaje. 2) La presentación tradicional, demanda que el ejecutante represente con la mayor exactitud al personaje, imitando sus actitudes en una escena extraída de la fuente mediática a la que pertenece el personaje y que pueda ser reconocida por el público, por lo tanto, el jurado presta mayor atención a los detalles tal y como se presentan en el anime, el manga o el videojuego correspondiente. Para precisar esta cuestión, se expondrá la presentación final con la que se llevó la victoria Fito Rey en la Comic Con $2013^{10}$.

Para el concurso, Fito Rey personificó a Kratos del videojuego God of war (Dios de la guerra) ${ }^{11}$. La puesta en escena se desarrolló con música de fondo en la que se destacan las voces de los personajes del juego (Kratos, Zeus y Gaia). Kratos inicia con la postura de batalla propia del personaje, como se presenta en la figura 2.

En la escena una voz femenina, Gaia (titánide de la tierra y narradora de la saga) descibe al público la situación en la que se encuentra Kratos, mientras el personaje permanece inmobil, tal como sucede en el juego. Al terminarse la narración de Gaia, Kratos inicia un diálogo con una voz masculina perteneciente a Zeus y como conclusión de este diálogo Kratos reta y amenaza de muerte al dios. Acto seguido, Kratos mira

9 Yamato Cosplay Cup es un concurso latinoamericano de cosplay que inició en Brasil, en octubre de 2009, con la colaboración de empresas de entretenimiento nipón.

10 Este concurso inicio hacia 1970 en Estados Unidos y en la actualidad tiene representación en diferentes países del mundo. En Colombia este evento se ha realizado en Medellín desde 2013.

11 Se trata de un juego que se basa en la mitología griega en la que Kratos (general espartano al servicio de los dioses de la mitología griega), debe recuperar sus poderes desafiando a los otros dioses (ver es.godofwar.wikia.com).
Figura 2. Kratos, presentación tradicional

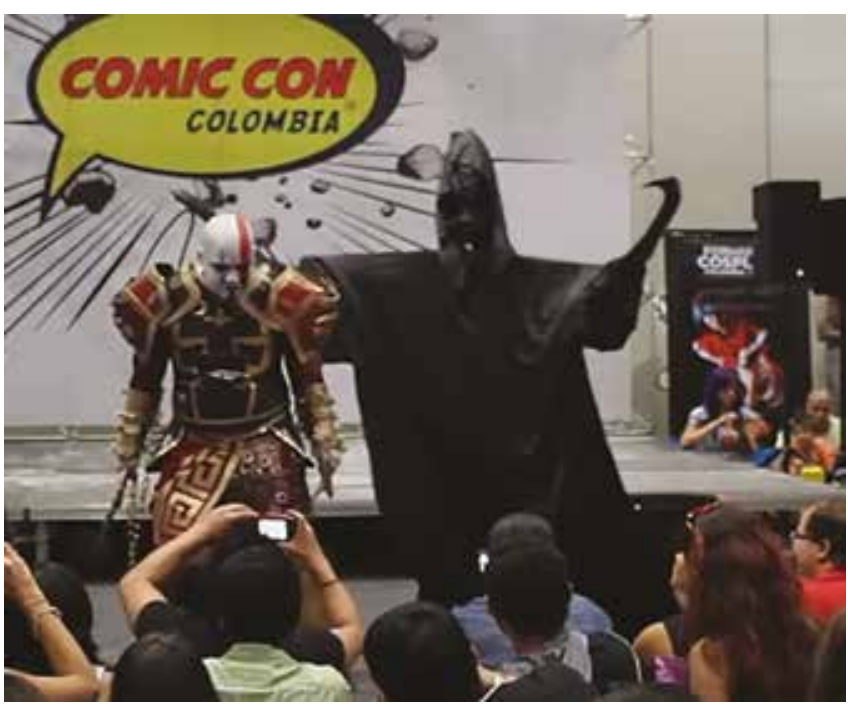

Fuente: elaboración propia

hacia el público que lo observa a través de las pantallas de los celulares, inmortalizando el momento en videos caseros y en fotografías que serán subidas a las redes sociales.

A continuación, Zeus envía los espectros invisibles del inframundo para matar a Kratos y nuevamente aparece la voz de Gaia, quién le advierte de las intenciones de Zeus. Kratos emprende la batalla y aparece un segundo personaje en escena, una especie de marioneta que simula el espectro con el que Kratos pelea. Los movimientos de la batalla causan en algunos espectadores murmullos y risas. Finalmente, Kratos vence al espectro arrancándole la cabeza. En la ultima escena, Kratos vuelve a retar al dios Zeus y vuelve a la misma posición con la que comenzó su presentación, entre los aplausos y gritos de satisfacción del publico. Pues bien, en una entrevista, Fito Rey define esta personificación como uno de los personajes más difíciles de caracterizar:

Primero por que yo soy gordo, cabezón, jorobado y Kratos es acuerpado, grande imponente y malvado y yo soy mas bien como agüevado. Entonces cuando me dicen "ay, queremos que te pongas a Kratos". Yo digo: "maldita sea", porque me toca fajarme, me toca ponerme un traje apretado, me toca ponerme un arnés, me toca afeitarme la cabeza y me toca usar maquillaje. Entonces yo digo "ok". Es difícil, me gusta, es chévere, pero no lo haría todos los días si mi vida dependiera de eso. (Radio Friky Emisora, 2014). 
Como se puede leer, Fito Rey se burla de sus características, se define como "feo" y reconoce caracteristicas estéticas al personaje que corresponden a ciertos cánones de belleza masculina: acuerpado, fuerte, agresivo. Aquí cabe preguntar: cuando se interpreta el personaje, ¿de qué modo y en qué medida, los intérpretes adquieren las caracteristicas estéticas del mismo? De un lado, el cuerpo es moldeado para encontrar una apariencia similar a la del personaje, pero, del otro, ese personaje se puede convertir en objeto de burla.

En efecto, la presentación libre permite una presentación construida desde la perspectiva del concursante. Algunos realizan reflexiones sobre el juego o el anime correspondiente y otros se permiten crear situaciones que no se verían en la versión original. La presentación libre de Fito Rey en el Comic Con 2013, realizada el mismo día y con el mismo personaje que la presentación tradicional, se convirtió en una sátira contra Kratos.

Al igual que lo que ocurrió en su presentación tradicional, Fito Rey se valió de una pista uyas voces describieron la situación. Al iniciar, aparece el personaje deambulando de un lado para otro, cuando la voz de un representante del centro de control de la ira, lo invita a bailar explicándole que la danza es una forma de controlar la furia. Hay que recordar que este personaje es un asesino que ha sido capaz de matar a su propia familia, así que el llamado de un asesor en control de la cólera es, en sí mismo, un acto irónico. Con los poderes otorgados por Orfeo (dios de la música y las artes) el narrador obliga a Kratos a bailar y cantar el Malambo n. ${ }^{0} 1^{12}$ de Ymac Sumac ${ }^{13}$. De este modo, se inicia una sitiación cómica que hace reir al publico ridiculizando a Kratos con movimientos sensuales involuntarios, aun así, mientras Kratos baila, continúa con la expresión de furia en su rostro, lo que hace muy graciosa la situación.

Vale la pena destacar que los elementos cómicos de la representación se desprenden del hecho de que un personaje masculino asume características femeninas (lo que no implica que se asocie con estereo-

12 "Mambo! es el quinto álbum de estudio de la soprano peruana Yma Sumac. Fue lanzado en 1954 por Capitol Records. Está compuesta enteramente por Moisés Vivanco". Tomado de http:// es.wikipedia.org/wiki/Mambo! 7/06/2015.

13 Soprano peruana nacida en 1922, descendiente directa de Atahualpa (ver https://bit.ly/2K2IHee).
Figura 3. Fito Rey, presentación libre

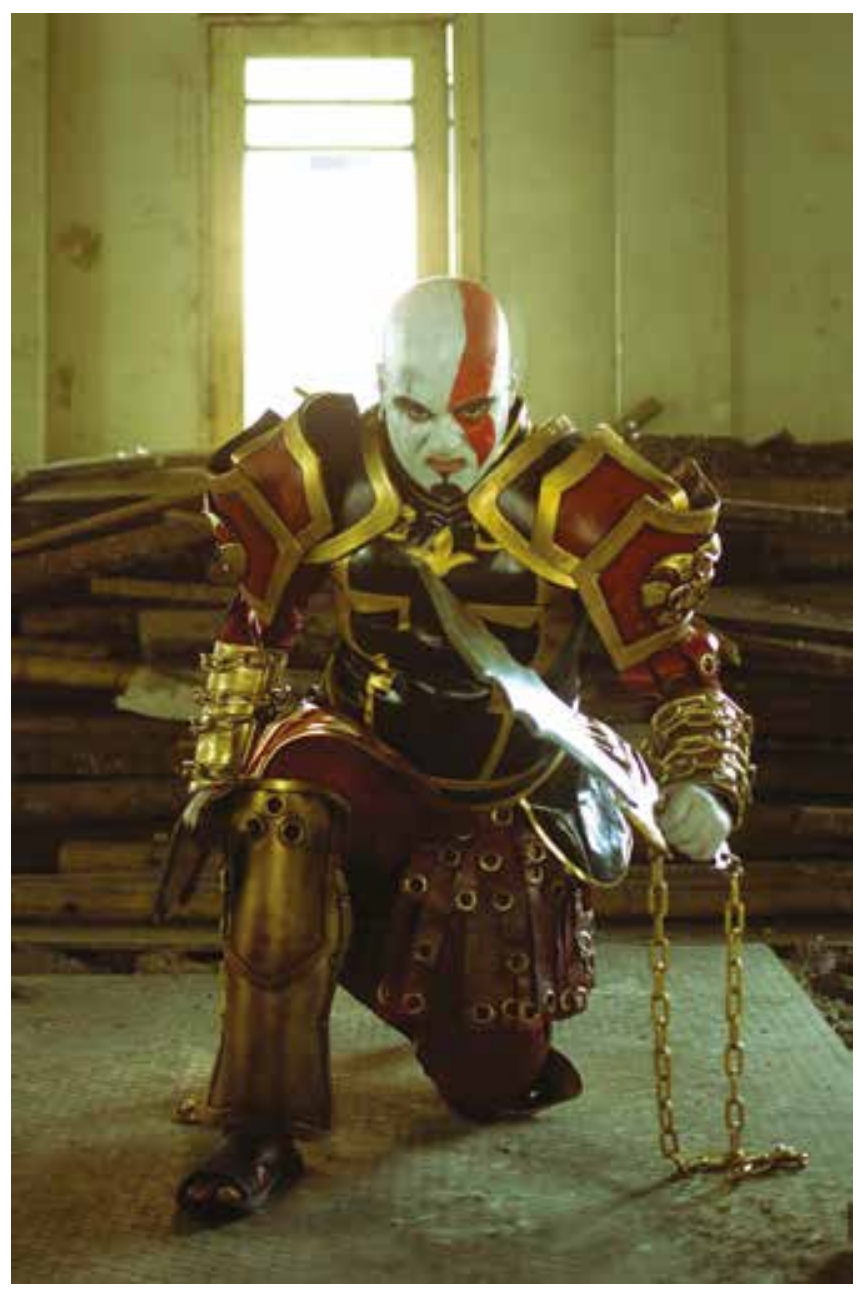

Fuente: archivo personal Fito Rey.

tipos gay). Kratos "rompe" momentáneamente con su masculinidad (fuerte, robusta) "obligado" por el narrador, revistiendo al personaje con una voz femenina y con características y movimientos sensuales y delicados que lo ponen en contacto con otro tipo de masculinidad. Lo gracioso se concentra en la transicion de un tipo de masculinidad a otra ridiculizando al personaje.

Estas escenas describen cómo los espectadores, los intérpretes y los personajes que representan crean una atmósfera lúdica que permite el "ingreso" al mundo de fantasía. Ahora bien, la descripción que hace Fito Rey de su propio personaje plantea una cierta tensión entre el modo como él se percibe (gordo, feo, agüevado) y las características de Kratos (fuerte y agresivo). Se trata de dos maneras de ser hombre, de dos lógicas de asumir la mascuilinidad, de hecho, la presentación libre se constituye en un ajuste de 
cuentas, en una "venganza" que aplica Rey contra su personaje: "[La representación libre es un] baile sexi donde estoy ridiculizando al pobre Kratos [...]. Yo me gozo más la presentación libre que la tradicional porque es donde uno puede decir 'voy a coger al personaje y le voy a hacer maldades'”. Entonces, la entrevistadora le pregunta: “¿Esa es tu venganza por tenerte que fajar y rapar la cabeza?”. Él responde: “exactamente” (Radio Friky Emisora, 2014).

Llama la atención que esta venganza alude al baile sexi, a la presentación de un personaje fuerte que exhibe algunas características femeninas. Entonces, de un lado, muchos personajes de fuentes mediaticas remiten a estereotipos masculinos como el que representa Kratos. De otro lado, este tipo de personajes han sido cuestionados por los intérpretes en sus interpretaciones libres. Sin embargo, se destaca el hecho de que las características femeninas confieran el contenido cómico: un personaje adquiere atribuciones que no le corresponden. Este juego de correspondencias es particulamente intenso en el cosplay. Así, por ejemplo, Fito Rey en el Yamato Cosplay encarnó a Rita Repulsa (personaje femenino) de la serie Power rangers: el público le preguntó que si él era una mujer. Fito Rey menciona que escoge a Rita Repulsa porque se adecuaba a su cuerpo, sin embargo, confiesa que "tenía miedo de pasar penas, de que dijeran 'mira a ese travesti'. Entonces para mi fue estresante, pero al mismo tiempo, yo dije 'tengo que impresionar a los jueces' y por eso escogí a Rita". Luego menciona que esta representación fue extraña para él: "a mi me da un poquito de pena que me digan 'quedaste hermosa', pues porque soy un hombre", pero cuando alguien del público exclamaba “ ¡no, no sabía que era un hombre!" el que intepretaba a Rita Repulsa, Fito entendía que "eso es un cumplido" y se decía a sí mismo "no eres una mujer, eres un hombre". La entrevistadora menciona que "eso sucede con el crossplay, uno no sabe qué decir: si lindo o linda" (Radio Friky Emisora, 2014).

\section{AMATEUR}

Para abordar esta categoría se hará referencia al evento de fotografía cosplay realizado en Bogotá en el Parque Nacional el domingo 24 de mayo del 2015, registrado en el marco de la presente investigación. Este evento fue organizado por cuatro comunidades nacionales de cosplay: 1) Dragon Ball, 2) Sailor Moon, 3) Saint Seya y 4) Naruto. Estas comunidades reciben el nombre de los protagonistas de los animes más reconocidos en Colombia.

Los cosplay que se presentaron en este evento pertenecen igualmente a las comunidades que representan, pero algunos de ellos hacen parte de las cuatro organizaciones. Su participación es libre y representan a los personajes que deseen interpretar. Como es obvio, sus representaciones son menos precisas que las de los profesionales, de modo que este tipo de eventos son más flexibles en cuanto al origen de los atuendos y la caracterización, aunque esto no implica que no exista un cierto rigor. A diferencia de los concursos, estos eventos permiten que los personajes y el público se mezclen, conversen, se tomen fotografías. Sin embargo, los personajes pueden realizar pequeñas interpretaciones que detienen el flujo de los espectadores, como se observa en la figura 4.

\section{Figura 4. Los fotógrafos}

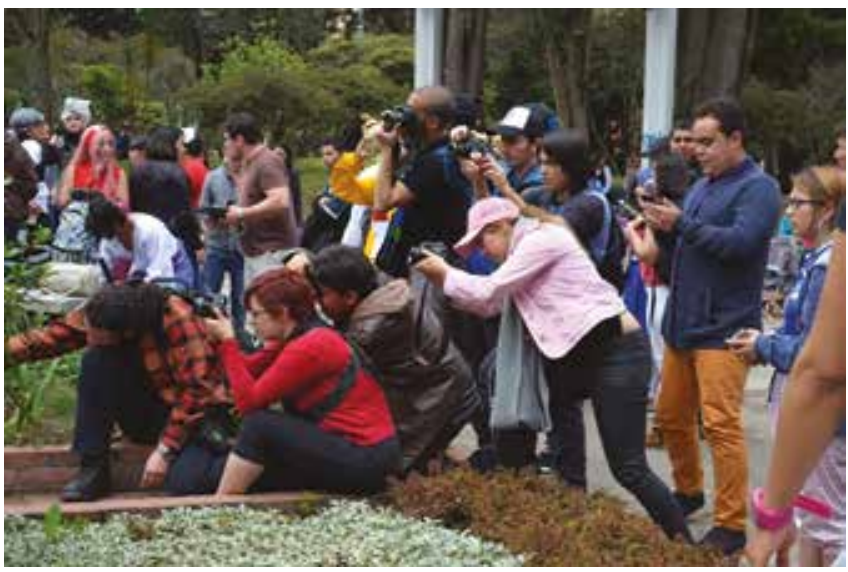

Fuente: elaboración propia.

Este tipo de interacción permite acercarse a las tensiones que diversos géneros del cosplay producen respecto a los roles de género. Así, por ejemplo, David Martínez representa a Sailor Moon en una caracterización de tipo Gender Bender (figura 5).

Frente a las apreciaciones del público respecto a su representación como Sailor Moon, David Martínez comenta: 


\section{Figura 5. Sailor Moon (cosplay, gender bender)}

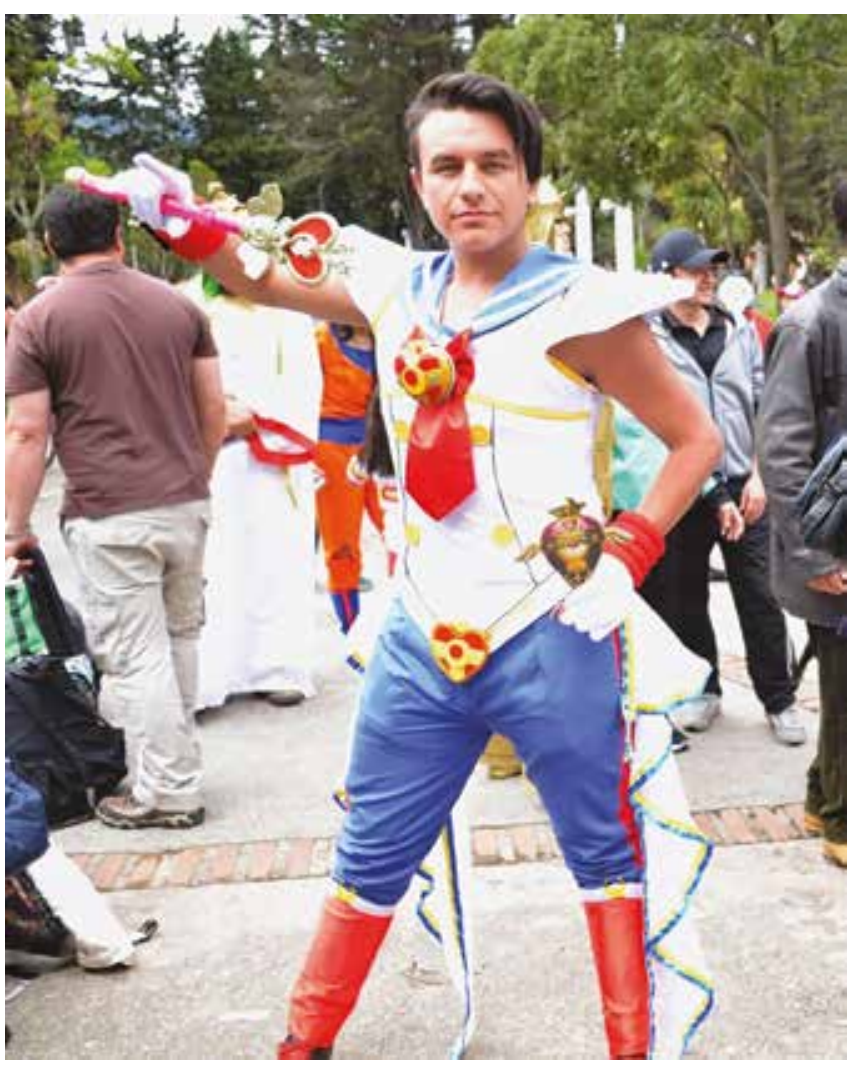

Fuente: elaboración propia.

Pues no faltan las personas que dicen que se ve mal, que se ve feo, pero la verdad es más el apoyo de las personas que conocen del tema, saben qué es un Gender Bender, entonces, pues lo asimilan más, lo reconocen más. Pero no faltan las personas que, por la falta de conocimiento, no les gusta [...] precisamente no quiero que mi género me impida presentar este personaje. (Entrevista en comunicación personal, 17 de mayo de 2015).

Según comenta, para algunos espectadores es difícil asumir que Sailor Moon sea personificada por un hombre. Aquí aparecen otros elementos respecto a la pregunta que se viene abordando: ¿cuál es, entonces, el sentido de las ficciones cosplay en relación con la construcción social del género? En otras palabras, ¿ de qué modo estas rupturas en la cotidianidad interpelan el devenir ordinario? En este sentido, las palabras de David Rincón (conocido en el ambiente como Taiki Kou $)^{14}$ son reveladoras:

14 Él es coadministrador de la comunidad Sailor Moon Colombia.
Lo que hacemos nosotros es, simplemente, mostrar lo que nos gusta, expresar unos gustos, expresar unos sentimientos y pues si alguno de los chicos expresa eso a través de un crossplay [hombres que interpretan personajes femeninos], entonces, eso demuestra, de alguna manera, que como comunidad nos estamos consolidando un poco más y que estamos también evolucionando, que estamos dejando toda la cantidad de prejuicios que nos impone la sociedad. (Entrevista en comunicación personal, 17 de mayo del 2015).

Así que este tipo de ejercicios, de transgresiones lúdicas que interrogan ciertos modos de ser hombre o de ser mujer, abren la posibilidad de que las rupturas con el orden de género hegemónico sean respetadas en el mundo cotidiano. Sin embargo, esta aceptación de las transgresiones es problemática.

\section{TRANSMILENIO}

Durante un evento el 17 de mayo del 2015, en el Parque Nacional de Bogotá, Gina Cepeda se presentó como Sailor Moon en su versión Usagi Tsukino. Gina viaja en Transmilenio y se toman una fotografía que se subió a Facebook, esta fue publicada luego por Publimetro con el siguiente título: “¿Sailor Moon, eres tú? La bogotaneada de la semana”.

Se trató de un artículo en el que se planteaba que un hombre usó el traje de Usagi Tsukino: "Aunque su parecido con la realidad no es realmente lo que se espera, este hombre hace alarde de su traje en la estación del Sistema”. El texto se burló de la representación de Gina, en lo que para los cosplayer fue un acto deningrante. Así, el Club Oficial Sailor Moon Colombia exige la rectificación del medio (que finalmente retira la publicación) a través de un comunicado que se titula: "¡Ya basta de irrespeto hacia la comunidad anime y cosplay en colombia!". El comunicado menciona en su parte central lo siguiente:

Exigimos disculpas públicas por parte de GLP, del diario Publimetro, del medio más cercano en Colombia (que es Caracol Radio) y el Grupo Prisa en Colombia, ante este hecho de total irrespeto hacia un ser humano. Realizando notas sin tener fuentes creíbles, y peor aún, burlarse así de los integrantes de la comunidad anime y cosplay en Colombia. (Comunidad Sailor Moon Colombia, 2015). 
Durante el evento del 17 de mayo, se entrevistó a Gina preguntándole por el sentido de su quehacer como cosplayer, ella respondió lo siguiente:

Aquí es todo libre, como uno se sienta feliz, como uno se sienta cómodo, aquí no importa si uno es alto, bajito, gordo, flaquito, hombre, mujer no importa, lo importante es que uno se sienta feliz y que uno pueda compartir con los demás ese gusto que tiene por anime. (Entrevista en comunicación personal, 17 de mayo del 2015)

Cuando se le preguntó por las expectativas del público frente a las representaciones, si el público espera que los intérpretes tengan unas características estéticas específicas y cómo lo resuelven los cosplayer, Gina comentó: "Pues, es [...] no ponerle cuidado a [...] cometarios mal intencionados, sino disfrutarlo, respetar todas las comunidades cosplay en Colombia". En efecto, ella participa de "una iniciativa que se llama Cosplay Respet, ¿Qué es eso? Respetar el cosplay sin importar como sea uno en su contextura física o su género lo importante es disfrutar, respetar y divertirse" (Entrevista en comunicación personal, 17 de mayo de 2015).

Todo este suceso permite plantear las dificultades de "trasladar" los juegos y transgresiones del generó a la vida cotidiana: las expectativas del público pueden colisionar con ellas, bien porque cuesta trabajo aceptar que un hombre realice una representación de personajes femeninos, bien porque esas representaciones deben limitarse a espacios y tiempos concretos, como ocurrió en el caso de Gina, quien se convirtió en objeto de burla a aparecer en un escenario cotidiano llevando el traje de su personaje favorito.

\section{FINALMENTE}

Cada categoría social (jóvenes, mujeres, hombres, niños) cuenta con unas características, con unos atributos. Los estigmas emergen cuando una persona no se adecúa a la categoría o no actúa de acuerdo con los atributos correspondientes (Goffman, 2006). Algunas personificaciones (encarnaciones) en el cosplay remiten a transgresiones lúdicas del género, esto es, a ciertas creaciones en escenarios extraordinarios frente a lo que se considera masculino o femenino. Se han identificado dos tipos de transgresiones en este caso: 1) en el personaje, atribuyendo características femeninas a personajes masculinos, y 2) en el intérprete, que un hombre asuma un personaje femenino. En ambos casos, se pone en juego la relación entre el cuerpo heredado y el cuerpo deseado, en cuanto relación compleja, pues no se trata solo de obtener ciertas características físicas, sino de "hacer lo que a uno le gusta" sin importar la estatura, el color de piel, etc., pues para algunos cosplayer su deseo de expresión se mueve más allá de los estereotipos.

De otro lado, el cosplay entrevé algunas de las tensiones que atraviesan el universo de lo deseable en el mundo contemporáneo: la relación compleja entre el mundo de lo lúdico (de lo extraordinario) y de lo cotidiano. De un lado, la personificación del cosplay se circunscribe a ciertas fronteras de tiempo y lugar, de modo que cuando se presentan por fuera de esas circunstancias, se producen tensiones y rechazos: se critica la tintura del cabello en los hombres, o se convierten en motivo de burla. De otro lado, el cosplay abre las posibilidades a nuevas masculinidades, en cuanto que promueve, en un cierto círculo de seguidores, la aceptación de personificaciones crossplayer.

El cosplay revela algunas complejas tensiones relacionadas con la exhibición de sí mismo, de lo que se ha denominado como extimidad, como construcción de una identidad alterdirigida: se trata de un proceso conflictivo que coloca a cada actor en la mira de los observadores. Se trata de una experiencia ética y estética en la que el encuentro con el otro (con el público o con otros cosplayer) y del otro (con personas que transgreden los cánones del género, la edad, o cualquier otra condición social), atraviesa la experiencia corporal: el vestido, los ademanes, las personificaciones, van de la mano con la exhibición, las críticas, las reflexiones personales, los reconocimientos y las disputas.

En otras palabras, aun cuando el cosplay se presenta como una opción de entretenimiento en la que los admiradores emulan a los personajes de recursos mediáticos como video juegos de la manera como el cuerpo se articula a la construcción del yo. De un lado, se trata de expresar el cuerpo deseado: se desea ser (encarnar), por un momento, un personaje. De otra parte, esta experiencia implica el encuentro con un público que expresa sus expectativas frente a los personajes, así como frente a quienes los interpretan, de ahí que se sientan sorprendidos cuando 
descubren que Rita Repulsa ha sido interpretada por un hombre y que Fito Rey tema que le juzguen como travesti, a pesar de reconocer en el cosplay una práctica libre en la que no importan los estereotipos.

Este carácter contencioso del espacio lúdico requiere de atención, pues esboza algunos aspectos claves del mundo contemporáneo: ¿cómo se cruzan las fantasías con el mundo ordinario?, ¿es posible crear alternativas sociales a través de los espacios de la fantasía y la creatividad, o estas creaciones quedan constreñidas a ciertos espacios y lugares, convertidas en el desahogo de unos cuantos? La diversidad, como exploración de las posibilidades de existir, se encuentra en juego.

\section{REFERENCIAS}

Butler, J. (1997). Lenguaje, poder e identidad. Madrid: Síntesis.

Castro-Gómez, S. (2009). Tejidos Oníricos. Movilidad, capitalismo y biopolítica en Bogotá (1910-1930). Bogotá: Pontificia Universidad Javeriana.

Castro-Gómez, S. y Restrepo, E. (2008). Introducción: Colombianidad, población y diferencia. En S. Castro-Gómez y E. Restrepo (eds.), Genealogías de la colombianidad. Formaciones discursivas y tecnologías de gobierno en los siglos XIX Y XX (pp. 10-40). Bogotá: Universidad Javeriana.

Comunidad Sailor Moon Colombia (22 de mayo de 2015). ¡Ya basta de irrespeto hacia la comunidad anime y cosplay en Colombia! [Actualización de estado de Facebook]. Recuperado de https://www.facebook.com/comunidadoficialsailormooncolombia/ posts/721127384662350/

Duch, Ll., y Mèlich, J. (2005). Escenarios de la corporeidad. Antropología de la vida cotidiana 2/1. Madrid: Trotta.

Ferrari, M. (2014). A emergência da cena cosplay nas culturas juvenis. Revista de Cultura Audiovisual, 41(41), 218-235.

García, A. (enero-junio, 2009). Tacones y siliconas, hormonas y otras críticas al sistema sexo/género. Feminismos y experiencias de transexuales y travestis. Revista Colombiana de Antropología, 45(1).

Goffman, E. (2006). Estigma. La identidad deteriorada. Buenos Aires: Amorrortu.

Gómez, R., y González, J. (2007). Relato a dos tiempos: herencias y emergencias de la apariencia corporal.
En Z. Pedraza (comp.), Políticas y estéticas del cuerpo en América Latina (pp. 259-284). Bogotá: Universidad de los Andes.

Jauss, H. (1992). ¿Qué significa experiencia estética? En Experiencia estética y hermenéutica literaria. Madrid: Taurus.

Mejía, O. (2009). Alienación, individuación e ideología. Bogotá: Universidad Nacional de Colombia.

Pedraza, Z. (2004). Intervenciones estéticas del yo. Sobre estético-política, subjetividad y corporalidad. En M. Laverde, G. Daza y M. Zuleta (eds.), Debates sobre el sujeto. Perspectivas contemporáneas (pp. 61-72). Bogotá: Universidad Central.

Pedraza, Z. (2007a). Introducción. Políticas y estéticas del cuerpo: la modernidad en América Latina. En Zandra Pedraza (comp.), Políticas y estéticas del cuerpo en América Latina (pp. 7-42). Bogotá: Universidad de los Andes.

Pedraza, Z. (2007b). Dejar nacer y querer vivir: gestión y gestación del cuerpo y de la vida. En Zandra Pedraza (comp.), Políticas y estéticas del cuerpo en América Latina (pp. 381-418). Bogotá: Universidad de los Andes.

Pedraza, Z. (2009). En clave corporal: conocimiento, experiencia y condición humana. Revista Colombiana de Antropología, 45(I), 147-168.

Pérez, A. (2009). Cuerpos tatuados, "almas" tatuadas: nuevas formas de subjetividad en la contemporaneidad. Revista Colombiana de Antropología, 45(I), 69-94.

Pinzón, C., Garay, G., y Suárez, R. (2004). Mundos en red. La cultura popular frente a los retos del siglo XXI. Bogotá: Universidad Nacional de Colombia.

Radio Friky Emisora, [rafiofrikyemisora]. (5 de agosto de 2014). Entrevista a los cosplayers Fito Rey y Larry moon. [Archivo de video]. Recuperado de https://www. youtube.com/watch?reload $=9 \& \mathrm{v}=\mathrm{Ssh} 8 \mathrm{UkmV} \_\mathrm{eU}$

Sibilia, P. (2009). La intimidad como espectáculo. Buenos Aires: Fondo de Cultura Económica.

Turner, B. (1989). El cuerpo y la sociedad: exploraciones en teoría social. México: Fondo de Cultura Económica.

Viveros, M. (2006). Introducción. ¿Qué significa hablar de género y sexualidad en América Latina? En Grupo de Estudios en Género, Sexualidad y Salud en América Latina, De mujeres, hombres y otras ficciones. Género y sexualidad en América Latina (pp. 13-29). Bogotá: Tercer Mundo Editores, Universidad Nacional de Colombia. 
